\title{
A Validated LC-MS/MS Assay for the Simultaneous Quantification of the FDA-Approved Anticancer Mixture (Encorafenib and Binimetinib): Metabolic Stability Estimation
}

\author{
Mohamed W. Attwa ${ }^{1,2}$, Hany W. Darwish ${ }^{1,3, *}$, Nasser S. Al-Shakliah ${ }^{1}$ and Adnan A. Kadi ${ }^{1}$ (D) \\ 1 Department of Pharmaceutical Chemistry, College of Pharmacy, King Saud University, P.O. Box 2457, \\ Riyadh 11451, Saudi Arabia; mzeidan@ksu.edu.sa (M.W.A.); nalshakliah@ksu.edu.sa (N.S.A.-S.); \\ akadi@ksu.edu.sa (A.A.K.) \\ 2 Students' University Hospital, The Pharmacy, Mansoura University, Mansoura 35516, Egypt \\ 3 Analytical Chemistry Department, Faculty of Pharmacy, Cairo University, Kasr El-Aini St., Cairo 11562, Egypt \\ * Correspondence: hdarwish@ksu.edu.sa; Tel.: +966-1146-77343
}

check for updates

Citation: Attwa, M.W.; Darwish, H.W.; Al-Shakliah, N.S.; Kadi, A.A. A Validated LC-MS/MS Assay for the Simultaneous Quantification of the FDA-Approved Anticancer Mixture (Encorafenib and Binimetinib): Metabolic Stability Estimation. Molecules 2021, 26, 2717. https:// doi.org/10.3390/molecules26092717

Academic Editor: Manuel Sergi

Received: 22 February 2021

Accepted: 28 April 2021

Published: 5 May 2021

Publisher's Note: MDPI stays neutral with regard to jurisdictional claims in published maps and institutional affiliations.

Copyright: (c) 2021 by the authors. Licensee MDPI, Basel, Switzerland. This article is an open access article distributed under the terms and conditions of the Creative Commons Attribution (CC BY) license (https:/ / creativecommons.org/licenses/by/ $4.0 /)$.

\begin{abstract}
The concurrent use of oral encorafenib (Braftovi, ENF) and binimetinib (Mektovi, BNB) is a combination anticancer therapy approved by the United States Food and Drug Administration (USFDA) for patients with BRAFV600E/V600K mutations suffering from metastatic or unresectable melanoma. Metabolism is considered one of the main pathways of drug elimination from the body (responsible for elimination of about $75 \%$ of known drugs), it is important to understand and study drug metabolic stability. Metabolically unstable compounds are not good as they required repetitive dosages during therapy, while very stable drugs may result in increasing the risk of adverse drug reactions. Metabolic stability of compounds could be examined using in vitro or in silico experiments. First, in silico metabolic vulnerability for ENF and BNB was investigated using the StarDrop WhichP450 module to confirm the lability of the drugs under study to liver metabolism. Second, we established an LC-MS/MS method for the simultaneous quantification of ENF and BNB applied to metabolic stability assessment. Third, in silico toxicity assessment of ENF and BNB was performed using the StarDrop DEREK module. Chromatographic separation of ENF, BNB, and avitinib (an internal standard) was achieved using an isocratic mobile phase on a Hypersil BDS $\mathrm{C}_{18}$ column. The linear range for ENF and BNB in the human liver microsome (HLM) matrix was $5-500 \mathrm{ng} / \mathrm{mL}\left(R^{2} \geq 0.999\right)$. The metabolic stabilities were calculated using intrinsic clearance and in vitro half-life. Furthermore, ENF and BNB did not significantly influence each other's metabolic stability or metabolic disposition when used concurrently. These results indicate that ENF and BNB will slowly bioaccumulate after multiple doses.
\end{abstract}

Keywords: binimetinib; encorafenib; LC-MS/MS; metabolic stability assessment; P450 module

\section{Introduction}

Melanoma is the most high-risk type of skin cancer. The relative survival rate (5 years) for patients with distant melanoma in the United States (US) is 23\% [1]. In 2018, the National Cancer Institute estimated that 91,270 new melanoma cases were diagnosed, and more than 9300 patients died of the disease in the US alone [2]. Cancer researchers are actively developing new treatments to improve patient outcomes for advanced melanoma. Specifically, the introduction of unique agents has sharply altered the treatment landscape for patients with all stages of melanoma. Available systemic treatments for patients with advanced melanoma include monoclonal antibodies, such as nivolumab that targets programmed cell death protein 1, and ipilimumab, which targets cytotoxic T-lymphocyte antigen-4, as well as oral small-molecule drugs that inhibit BRAF or MEK proteins [3].

The mitogen-activated protein kinase (MAPK) signaling pathway has a vital role in melanoma progression [4]. This pathway's activation generates a signal cascade that results 
in sequential phosphorylation and activation of MAPK kinases, such as rat sarcoma (RAS), and the serine/threonine kinases rapidly accelerating fibrosarcoma (RAF), extracellular signal-regulated kinase (ERK), and MAPK/ERK kinase (MEK). These kinases regulate various cellular activities involving cell migration, proliferation, differentiation, angiogenesis, and survival. This pathway's abnormal signaling can result in uncontrolled cell transformation and growth [5] and various cancer types. Activating BRAF mutations are found in approximately $20 \%$ of mucosal melanomas and $50 \%$ of skin melanomas [6].

Binimetinib (Mektovi, BNB), a MEK inhibitor, and encorafenib (Braftovi, ENF), a BRAF inhibitor, are two orally bioavailable drugs established by Array BioPharma that are used for treating melanoma (Figure 1). ENF blocks the activity of a molecule called BRAF (mutated form). BNB stops a MEK molecule; MEK and BRAF are important protein molecules in cell growth regulation. BRAF V600K and V600E mutations signal for cells to begin abnormal growth and out-of-control splitting. These cells can be converted to a melanoma tumor, and approximately $50 \%$ of all melanomas have a BRAF mutation. MEK receives signals from BRAF and other molecules in the cell. In melanoma treatment, ENF stops the signaling pathway of the V600E-mutated BRAF molecule. BNB stops V600E- or V600K-mutated BRAF molecule signaling through the MEK molecule. Stopping BRAF and MEK molecules is more efficient than stopping BRAF alone [6,7]. The USFDA approved ENF combined with BNB (27 June 2018) for patients with BRAFV600E/V600K mutations and metastatic or unresectable melanoma [8]. The pivotal clinical trial, COLUMBUS, supported the approval of ENF combined with BNB for this indication [9]. The recommended oral doses are $450 \mathrm{mg}$ ENF, once daily, and $45 \mathrm{mg}$ BNB, twice daily [10].<smiles>Cn1cnc2c(F)c(Nc3ccc(Br)cc3F)c(C(=O)NOCCO)cc21</smiles>

Binimetinib

Molecular Weight: 441.23<smiles>C=CC(=O)Nc1cccc(Oc2nc(Nc3ccc(N4CCN(C)CC4)c(F)c3)nc3[nH]ccc23)c1</smiles>

Avitinib (IS)

Molecular Weight: $487.54 \quad$ Molecular Weight: 540.01

Figure 1. Chemical structures of binimetinib (BNB), avitinib (AVB), and encorafenib (ENF).

Metabolism is considered one of the main pathways of drug elimination in human organs (responsible for the excretion of about 75\% of known drugs) [11,12]. Therefore, metabolism can be the reason for problems with drug-drug interactions, bioavailability, and inter-individual differences [13,14], so it has a major influence in drug design [15]. Metabolic stability is considered one of the most important metabolism parameters that describes the vulnerability of compounds to metabolism. A metabolic stability study is an important step in the drug design pipeline when deciding on a drug's acceptance or rejection [16]. Hence, it is important not only to characterize metabolites of drug candidates (studying their pharmacological activity and toxicity), but also metabolic stability of potential compounds, resulting in increasing drug acceptance rate thanks to performing many studies on increasing drugs' metabolic stability [17]. Metabolic stability is expressed by various values (such as half-life or intrinsic clearance). Metabolic stability allows the assessment of how long a drug can be stable in a studied system, including in vitro and in vivo studies. Additionally, in silico approaches have been developed to predict in vitro half-life such as the StarDrop WhichP450 module software package [18-20]. 
Although several recent studies have discussed long-term severe adverse events after this combined therapy [21,22], the treatment of BRAF V600 melanoma combined with these two drugs appears advantageous compared with alternative treatments $[8,23,24]$. Therefore, developing a fast and reliable analytical method for the simultaneous estimation of BNB and ENF is essential. Metabolic stability studies are important tools for understanding drug metabolism; if a drug is moderately metabolized, it can have good bioavailability in vivo [25]. Additionally, studying the metabolic stability of the BNB and ENF combination may give insight into any mutual effect that the drugs' metabolic stability may have.

Since both ENF and BNB are liver metabolized, it is, therefore, probable that the two drugs might affect each other's metabolic stability [6-8]. This study's primary aim is to investigate the effect of each component drug of the mixture on the metabolic stability of the other [25]. BNB and ENF were previously quantified in human plasma [26,27]. There is only one published article on the simultaneous analysis of BNB and ENF in pure pharmaceutical ingredients and formulations, but the linearity was 2-20 and 6-20 $\mathrm{\mu g} / \mathrm{mL}$ for BNB and ENF, respectively, which does not reach the required limit for metabolic stability studies [28,29]. Thus, an appropriate and validated liquid chromatography-tandem mass spectrometry (LC-MS/MS) assay for the simultaneous detection and quantification of BNB and ENF in the biological matrix (human liver microsomes) was developed to achieve the required quantification limit [30-32]. Such a method is probably useful for calculating intrinsic clearance (CLint) and in vitro half-life $\left(\mathrm{t}_{1 / 2}\right)$ [33] for metabolic stability assessments.

As an initial step, in silico metabolic vulnerability for the mixture's two components was performed using the StarDrop WhichP450 module software package to predict such data. For the estimation of in vivo metabolic clearance rate from in vitro intrinsic clearance data, three basic models, dispersion, venous equilibrium, and parallel tube, could be used [34,35]. In this study, the metabolic stability of ENF and BNB involving intrinsic clearance and in vitro $t_{1 / 2}$ in HLMs was computed according to the in vitro half-life approach, using the well-stirred model [36,37], as it is considered the most widely used model for in vitro drug metabolism experiments due to its simplicity. These in vitro parameters (in vitro $t_{1 / 2}$ and intrinsic clearance) could be used for calculating different physiological parameters (in vivo $t_{1 / 2}$ and hepatic clearance).

\section{Results and Discussion}

\subsection{Results of In Silico ENF and BNB Metabolic Stability}

The metabolic landscapes for ENF and BNB indicate the lability of each site with respect to metabolism by CYP3A4 in absolute terms, to guide the optimization of chemical structure for improving metabolic stability. Composite site lability (CSL) values of BNB and ENF were 0.9775 and 0.9108 , respectively, which indicates the lability of both drugs to metabolism by the liver. These values indicate that BNB and ENF are expected to be moderately metabolized in the liver, matching with the in vitro metabolic stability study. In BNB, C26 of the hydroxyl group was predicted to be the main labile site of metabolism, indicating the metabolic stability of BNB. The other metabolic soft spots are stable. In ENF, C36 of the methoxyl group and C29 and C30 of the 2-propanyl groups were predicted to be the main labile sites of metabolism, indicating the metabolic stability of ENF. The other metabolic soft spots are stable. The result from the Which $4450^{\mathrm{TM}}$ module, shown by the pie chart, was used for indication of the most likely cyp450 isoform that has a major role in BNB and ENF metabolism (Figures 2 and 3). Cyp3A4 was found to have a major role in ENF and BNB metabolism. In silico results were supported by the experimental work that indicated the metabolic stability of ENF and BNB. According to pharmacokinetic information of encorafenib and binimetinib, CYP3A4 has a major role in encorafenib and binimetinib metabolism. 

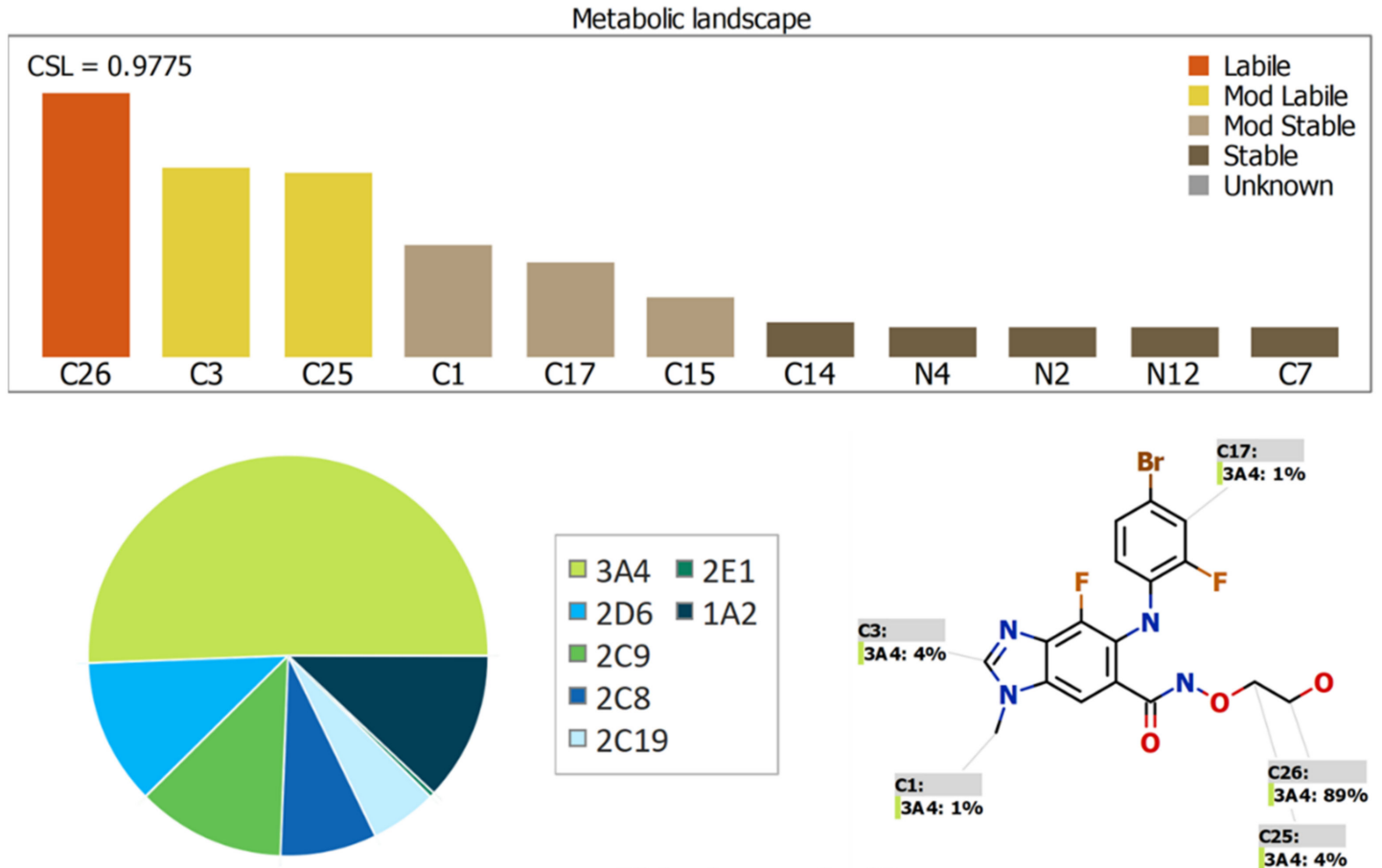

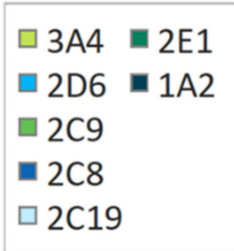

\section{Binimetinib}

Figure 2. Proposed metabolic sites for BNB by StarDrop WhichP450 ${ }^{\mathrm{TM}}$ module.

Metabolic landscape
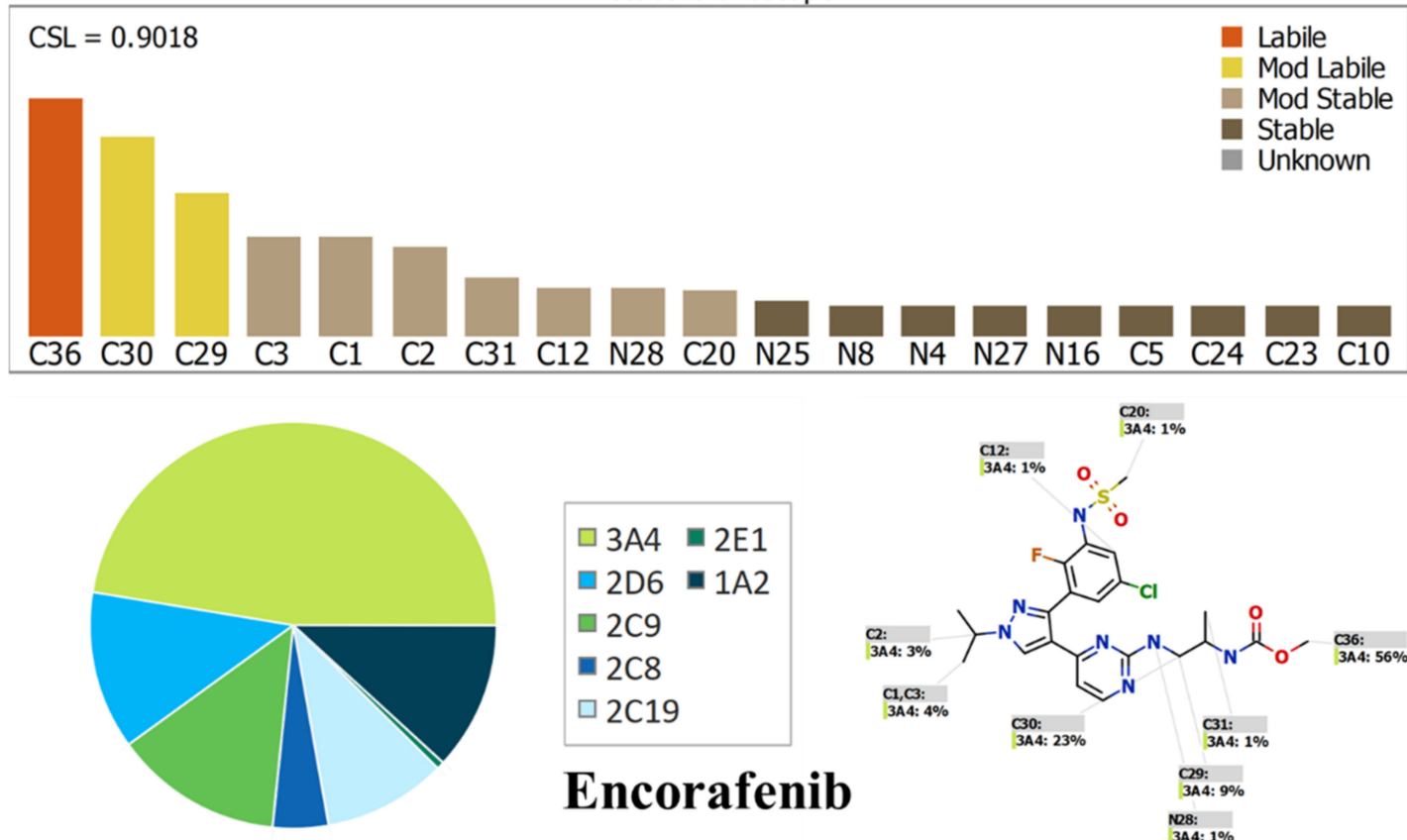

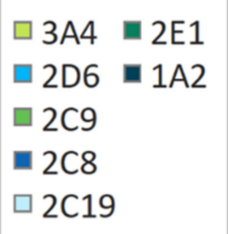

Encorafenib

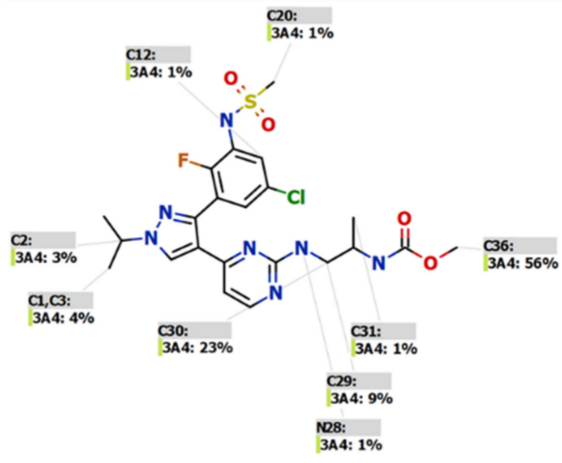

Figure 3. Proposed metabolic sites for ENF by StarDrop WhichP450 ${ }^{\mathrm{TM}}$ module.

\subsection{Results of In Silico BNB and ENF Structural Alert Sites and Toxicity Prediction}

In silico toxicity assessments of BNB and ENF were carried out using DEREK software. BNB shows structural alerts that cause proposed side effects, including nephrotoxicity (equivocal) due to halogenated benzene (Figure 4). ENF shows structural alerts that cause proposed side effects, including hepatotoxicity (plausible) and phototoxicity (equivocal) due to carbamate and 1,3,5-hexatriene, respectively (Figure 3). 
Binimetinib

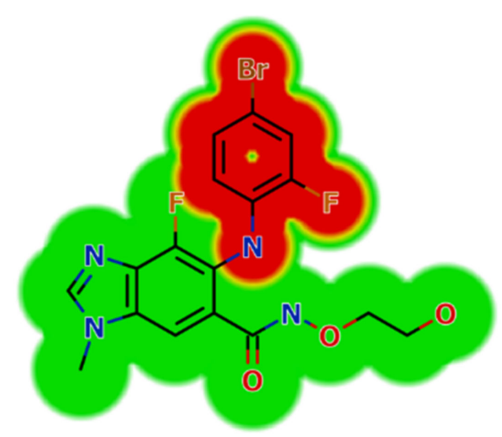

Nephrotoxicity

EQUIVOCAL

Halogenated benzene

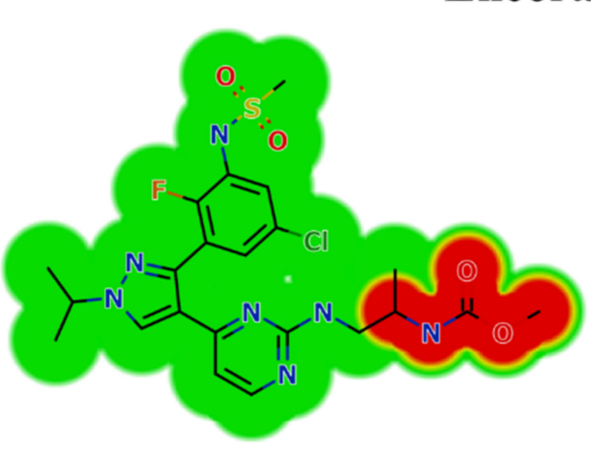

Hepatotoxicity

PLAUSIBLE

Carbamate

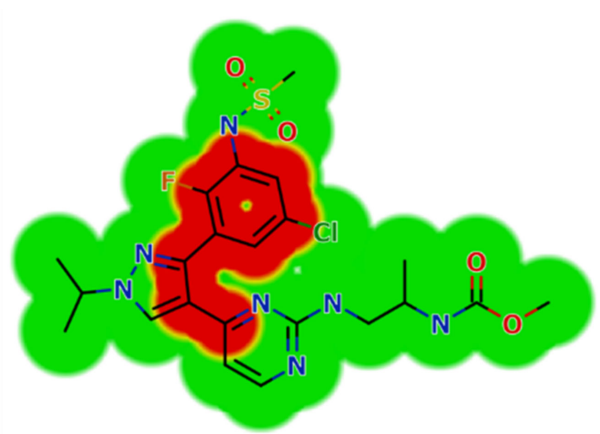

\section{Phototoxicity \\ EQUIVOCAL \\ 1,3,5-Hexatriene}

Figure 4. DEREK outcomes showing structural alerts with the proposed side effects of ENF and BNB. Red indicates the structural alerts.

\subsection{HPLC-MS/MS Methodology}

We optimized all chromatographic parameters involving the mobile phase constituents, mobile phase $\mathrm{pH}$, and stationary phase. The $\mathrm{pH}$ of the aqueous mobile phase portion (10 mM ammonium formate) was optimized to 3.8 with formic acid, as higher $\mathrm{pH}$ values led to peak tailing and an unnecessary increase in elution time. The optimized mobile phase consisted of $38 \%$ aqueous and $62 \% \mathrm{ACN}$, as higher proportions of ACN reduced the resolution of the chromatographic peaks and lower proportions of ACN increased elution time. We tested the use of different stationary phases, such as HILIC columns, but such stationary phases were unable to retain or separate ENF, BNB, or AVB; however, good results were achieved using Thermo Scientific Hypersil BDS $\mathrm{C}_{18}$ columns. Figure 5 shows the MRM mass spectra for ENF, BNB, and AVB with their corresponding fragmentation patterns.

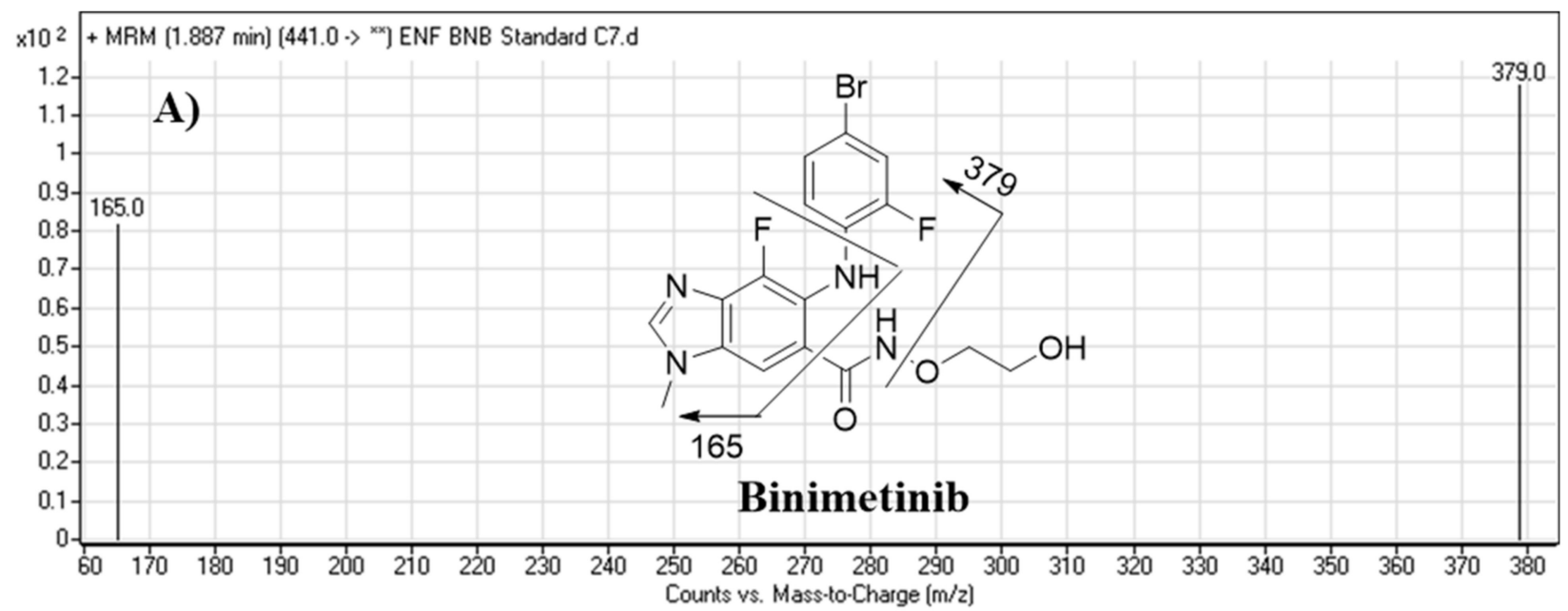

Figure 5. Cont. 

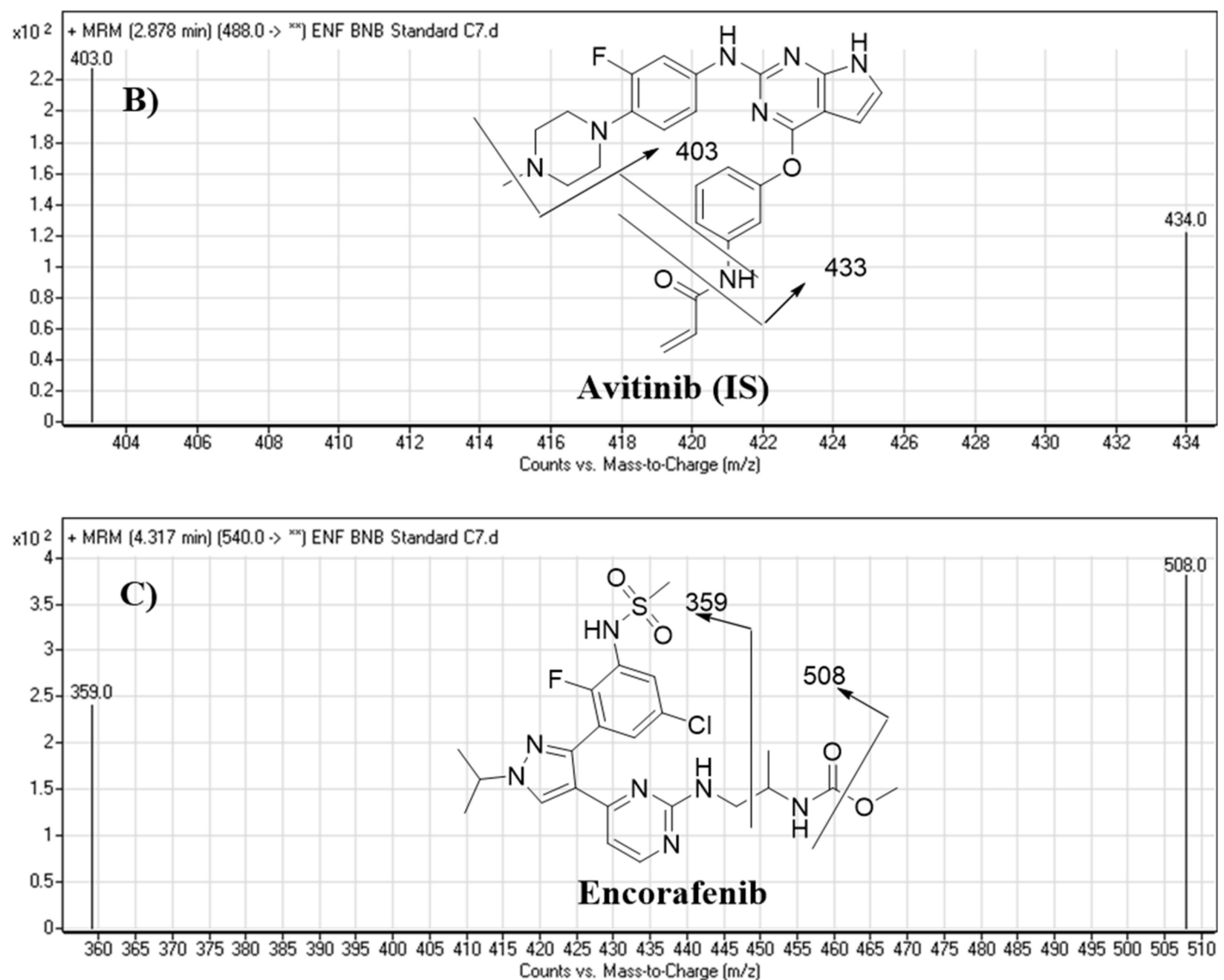

Figure 5. MRM mass transitions (parent to daughter ions) of BNB (A), AVB (IS) (B), and ENF (C) showing the selected daughter ions.

\subsection{LC-MS/MS Method Validation}

\subsubsection{Specificity}

The chromatographic peaks of BNB, ENF, and AVB were eluted at different retention times. No overlapping peaks from the HLM blank were seen during the elution times of analytes. Chromatographic separation of ENF, BNB, and AVB was achieved with good resolution over a run time of $6 \mathrm{~min}$ (Figure 6). The MRM chromatograms showed good peak resolution of each analyte (ENF, BNB, and AVB) and an absence of peaks from the control HLM matrix at the corresponding retention times; these data confirm the specificity of the developed LC-MS/MS methodology.

\subsubsection{Sensitivity and Linearity}

We established a linear range for the method from $5 \mathrm{ng} / \mathrm{mL}$ (LLOQ) to $500 \mathrm{ng} / \mathrm{mL}$ (upper limit of quantification; ULOQ) in the HLM matrix. Thirteen analyte standards were prepared, ten of them were used as calibration standards and three were used as quality controls. Six calibration curves of BNB and ENF were prepared on the first day of validation. The average from all data was used to establish a calibration curve for $\mathrm{BNB}$ and ENF. The regression equation for the ENF calibration curve was $\mathrm{y}=2.3299 \mathrm{x}-$ $4.5808\left(R^{2}=0.9998\right)$. The standard error of the slope and intercept were 0.007089 and 1.501 , respectively. The regression equation for the BNB calibration curve was $\mathrm{y}=0.5287 \mathrm{x}-$ $2.2924\left(R^{2}=0.9997\right)$. The standard error of the slope and intercept were 0.0006829 and 
0.1446 , respectively. The lower limit of quantification was $5 \mathrm{ng} / \mathrm{mL}$ for both the ENF and BNB calibration curves. The relative standard deviation (RSD) values of six replicates for each standard concentration in the HLM matrix was less than $1.65 \%$ for ENF and less than $2.92 \%$ for BNB (Table 1). We performed back-calculations of the six calibration curves (calibration standards) and quality control (QC) samples of ENF and BNB in the HLM matrix, which showed good performance of the methodology. The results of the six calibration curves were used for linearity confirmation and intra-day validation. The relative standard deviation (RSD) values of calibration standards and quality controls in the HLM matrix were less than $1.65 \%$ for ENF and less than $2.92 \%$ for BNB (Table 1).

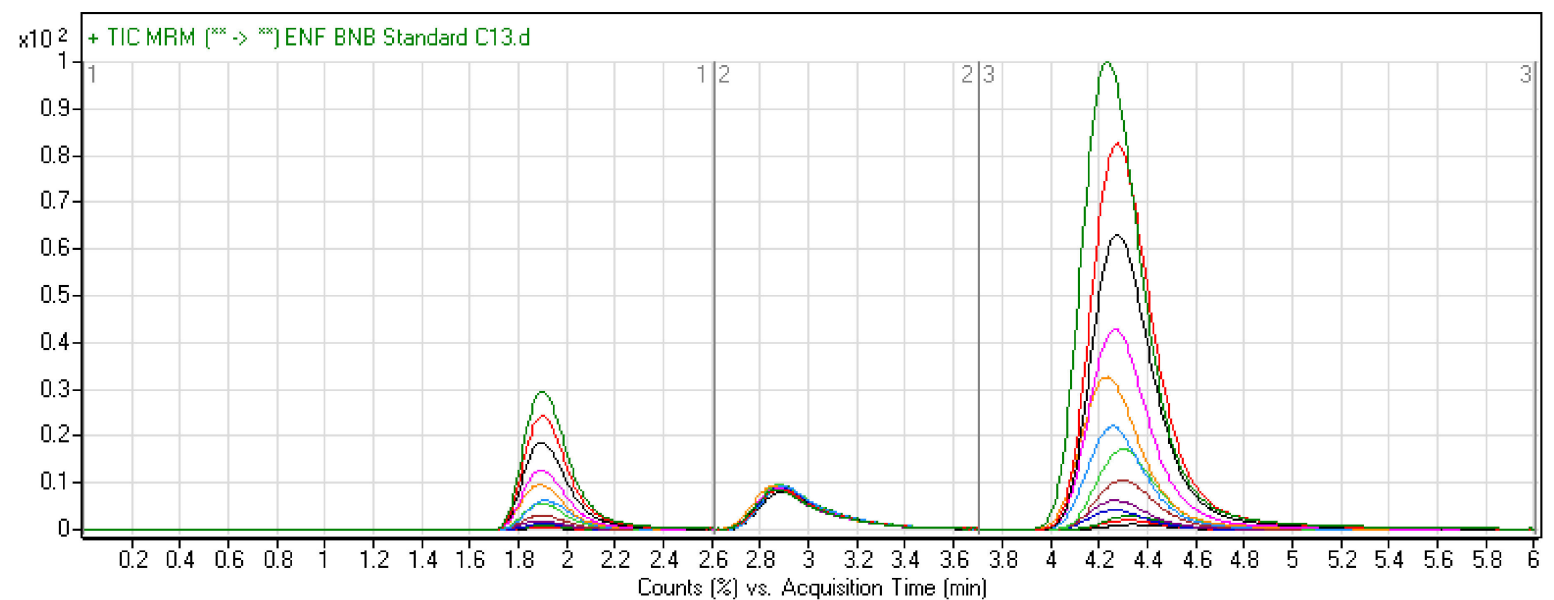

Figure 6. Overlaid MRM chromatograms of BNB at concentrations of 5.0-500.0 ng/mL at 1.89 min, AVB at a concentration of $100 \mathrm{ng} / \mathrm{mL}$ at $2.88 \mathrm{~min}$, and ENF at concentrations of 5.0-500 $\mathrm{ng} / \mathrm{mL}$ at $4.32 \mathrm{~min}$. Standards and QC levels are exhibited in different colors: 500 (green), 400 (red), 300 (black), 200 (fuchia), 150 (orange), 100 (aqua), 80 (lime), 50 (maroon), 30 (purple), 20 (blue), 15 (olive), 10 (light red), and 5 (dark gray).

Table 1. ENF and BNB concentration data back-calculated from the HLM matrix calibration levels.

\begin{tabular}{|c|c|c|c|c|c|c|c|c|}
\hline \multirow{2}{*}{$\begin{array}{c}\text { Concentration in } \\
\mathrm{ng} / \mathrm{mL}\end{array}$} & \multicolumn{4}{|c|}{ BNB } & \multicolumn{4}{|c|}{ ENF } \\
\hline & Mean $^{a}$ & SD & RSD \% & Accuracy \% & Mean $^{a}$ & SD & RSD \% & Accuracy \% \\
\hline 5 & 5.72 & 0.13 & 2.27 & 114.35 & 5.70 & 0.04 & 0.63 & 113.94 \\
\hline 10 & 10.09 & 0.36 & 3.58 & 100.93 & 10.56 & 0.06 & 0.57 & 105.57 \\
\hline 15 (LQC) & 14.98 & 0.24 & 1.60 & 99.84 & 15.24 & 0.14 & 0.94 & 101.63 \\
\hline 20 & 19.46 & 0.36 & 1.86 & 97.29 & 20.17 & 0.35 & 1.75 & 100.86 \\
\hline 30 & 29.62 & 0.32 & 1.08 & 98.75 & 30.80 & 0.18 & 0.57 & 102.66 \\
\hline 50 & 49.48 & 1.41 & 2.85 & 98.96 & 49.87 & 0.76 & 1.52 & 99.75 \\
\hline 80 & 82.15 & 2.40 & 2.92 & 102.69 & 79.06 & 1.30 & 1.65 & 98.83 \\
\hline 100 & 98.21 & 1.36 & 1.39 & 98.21 & 97.41 & 0.77 & 0.79 & 97.41 \\
\hline 150 (MQC) & 148.71 & 1.51 & 1.02 & 99.14 & 149.30 & 0.83 & 0.55 & 99.53 \\
\hline 200 & 200.18 & 1.42 & 0.71 & 100.09 & 199.68 & 1.47 & 0.74 & 99.84 \\
\hline 300 & 303.91 & 5.47 & 1.80 & 101.30 & 302.84 & 1.00 & 0.33 & 100.95 \\
\hline 400 (HQC) & 396.97 & 2.22 & 0.56 & 99.24 & 400.59 & 3.46 & 0.86 & 100.15 \\
\hline 500 & 500.44 & 2.89 & 0.58 & 100.09 & 498.75 & 2.08 & 0.42 & 99.75 \\
\hline$\%$ Recovery & & & & 100.84 & & & & 101.61 \\
\hline SD & & & & 4.29 & & & & 4.20 \\
\hline
\end{tabular}

\footnotetext{
${ }^{a}$ Average of the results of six calibrations and quality control standards.
} 


\subsubsection{Precision and Accuracy}

The intra-day and inter-day precision and accuracy values were $0.45-2.60 \%$ and $96.11-$ $100.25 \%$ for ENF, and $0.46-2.48 \%$ and $99.14-104.31 \%$ for BNB; these values are within acceptable ranges according to FDA guidelines for pharmaceuticals (Table 2).

Table 2. Intra-day and inter-day accuracy and precision.

\begin{tabular}{|c|c|c|c|c|c|c|c|}
\hline & & HLM Matrix & & Mean & SD & $\%$ RSD & $\%$ Accuracy \\
\hline \multirow{6}{*}{ BNB } & \multirow{2}{*}{\multicolumn{2}{|c|}{15.00 (LQ) }} & Intra-day assay * & 14.98 & 0.20 & 1.31 & 99.8 \\
\hline & & & Inter-day assay ${ }^{* *}$ & 15.02 & 0.37 & 2.48 & 104 \\
\hline & \multirow{6}{*}{$\begin{array}{l}\text { Conc. in } \\
\mathrm{ng} / \mathrm{mL}\end{array}$} & \multirow{2}{*}{$150.00(\mathrm{MQ})$} & Intra-day assay & 148.71 & 1.24 & 0.83 & 99.1 \\
\hline & & & Inter-day assay & 148.68 & 1.37 & 0.92 & 100 \\
\hline & & \multirow{2}{*}{400.00 (HQ) } & Intra-day assay & 396.97 & 1.81 & 0.46 & 99.2 \\
\hline & & & Inter-day assay & 397.78 & 3.52 & 0.88 & 101 \\
\hline \multirow{6}{*}{ ENF } & & \multirow{2}{*}{15.00 (LQ) } & Intra-day assay & 15.24 & 0.12 & 0.77 & 101 \\
\hline & & & Inter-day assay & 15.16 & 0.39 & 2.60 & 96.1 \\
\hline & & \multirow{2}{*}{150.00 (MQ) } & Intra-day assay * & 149.30 & 0.67 & 0.45 & 99.5 \\
\hline & & & Inter-day assay & 148.20 & 1.88 & 1.27 & 96.7 \\
\hline & & \multirow{2}{*}{400.00 (HQ) } & Intra-day assay & 400.59 & 2.83 & 0.71 & 100 \\
\hline & & & Inter-day assay & 399.80 & 2.92 & 0.73 & 100 \\
\hline
\end{tabular}

* Average of 12 replicates of day 1. ${ }^{* *}$ Average of six replicates in three consecutive days.

\subsubsection{Matrix Effects and Extraction Recovery}

The recoveries of ENF and BNB from the HLM matrix were $100.1 \% \pm 1.1 \%$ and $99.73 \% \pm 0.78 \%$, respectively (Table 3 ). The HLM matrix did not influence the ionization of analytes. We found matrix effects of $99.12 \% \pm 3.2 \%$ for BNB and $98.7 \% \pm 2.1 \%$ for ENF. These results show that the HLM matrix exerts only minor effects on the ionization of ENF, BNB, and AVB (IS), and the extraction procedure using ACN shows a highly efficient procedure for extracting BNB and ENF for the HLM matrix.

Table 3. Recovery of QC samples in the HLM matrix.

\begin{tabular}{ccccccc}
\hline \multirow{2}{*}{$\begin{array}{c}\text { Concentration } \\
(\mathbf{n g} / \mathbf{m L})\end{array}$} & \multicolumn{7}{c}{ HLM Matrix } \\
\cline { 2 - 7 } & $\mathbf{1 5}$ & $\mathbf{1 5 0}$ & $\mathbf{4 0 0}$ & $\mathbf{1 5}$ & $\mathbf{1 5 0}$ & $\mathbf{4 0 0}$ \\
\cline { 2 - 7 } & 15.09 & 148.56 & 398.35 & 15.15 & 148.40 & 400.35 \\
\hline Mean $^{\text {a }}$ & 100 & 99.1 & 99.6 & 101 & 98.9 & 100 \\
\hline Recovery (\%) & 0.38 & 1.30 & 3.55 & 0.36 & 1.79 & 3.03 \\
\hline SD & 2.51 & 0.87 & 0.89 & 2.38 & 1.21 & 0.76 \\
\hline Precision (RSD \%) & & & & & &
\end{tabular}

\subsubsection{Stability}

We evaluated the stability of ENF and BNB in deactivated HLM matrix (1 mg protein $/ 1 \mathrm{~mL}$ phosphate buffer) under common laboratory storage conditions. Analyte stability evaluation was performed in different conditions: Room temperature for $8 \mathrm{~h}$, three freeze-thaw cycles, storage at $4{ }^{\circ} \mathrm{C}$ for $24 \mathrm{~h}$, and storage at $-20{ }^{\circ} \mathrm{C}$ for $30 \mathrm{~d}$. Measured values were $96.55-101.64 \%$ for ENF and $96.79-100.05 \%$ for BNB. Stability data for ENF and BNB are described in Table 4 . We did not observe analyte degradation under the tested conditions. The stability data reveal that the LC-MS/MS method could be successfully used for assaying ENF and BNB without noticeable loss. 
Table 4. Stability of ENF and BNB in the HLM matrix (1 mg/1 mL phosphate buffer) under different laboratory conditions.

\begin{tabular}{|c|c|c|c|c|}
\hline & $\begin{array}{l}\text { Nominal Concentration } \\
\text { (ng/mL) }\end{array}$ & Mean (ng/mL) & Recovery \% & Precision (RSD \%) \\
\hline \multirow{16}{*}{$\mathrm{BNB}$} & Room temperature for $8 \mathrm{~h}$ & \multirow{2}{*}{$14.89 \pm 0.2$} & \multirow{2}{*}{99.25} & \multirow{2}{*}{3.07} \\
\hline & 15 & & & \\
\hline & 150 & $147.38 \pm 2.74$ & 98.25 & 1.70 \\
\hline & 400 & $395.31 \pm 4.14$ & 98.85 & 1.23 \\
\hline & Three freeze-thaw cycles & \multirow{2}{*}{$14.75 \pm 0.27$} & \multirow{2}{*}{98.32} & \multirow{2}{*}{0.46} \\
\hline & 15 & & & \\
\hline & 150 & $145.18 \pm 2.04$ & 96.79 & 2.52 \\
\hline & 400 & $389.91 \pm 3.19$ & 97.48 & 4.87 \\
\hline & Stored at $4{ }^{\circ} \mathrm{C}$ for $24 \mathrm{~h}$ & \multirow{2}{*}{$15.01 \pm 0.42$} & \multirow{2}{*}{100.05} & \multirow{2}{*}{2.80} \\
\hline & 15 & & & \\
\hline & 150 & $146.38 \pm 3.99$ & 97.59 & 2.73 \\
\hline & 400 & $397.31 \pm 4.89$ & 99.33 & 1.23 \\
\hline & Stored at $-20{ }^{\circ} \mathrm{C}$ for 30 days & & & \\
\hline & 15 & $14.51 \pm 0.67$ & 96.72 & 4.59 \\
\hline & 150 & $146.58 \pm 2.39$ & 97.72 & 1.63 \\
\hline & 400 & $395.11 \pm 4.57$ & 98.78 & 1.16 \\
\hline \multirow{16}{*}{ ENF } & \multicolumn{4}{|l|}{ Room temperature for $8 \mathrm{~h}$} \\
\hline & 15 & $15.25 \pm 0.3$ & 101.64 & 2.00 \\
\hline & 150 & $150.83 \pm 4.17$ & 100.55 & 2.76 \\
\hline & 400 & $405.84 \pm 4.45$ & 101.46 & 1.10 \\
\hline & \multicolumn{4}{|l|}{ Three freeze-thaw cycles } \\
\hline & 15 & $14.61 \pm 0.26$ & 97.37 & 1.80 \\
\hline & 150 & $145.83 \pm 3.93$ & 97.22 & 2.70 \\
\hline & 400 & $398.64 \pm 3.95$ & 99.66 & 0.99 \\
\hline & \multicolumn{4}{|l|}{ Stored at $4{ }^{\circ} \mathrm{C}$ for $24 \mathrm{~h}$} \\
\hline & 15 & $14.51 \pm 0.35$ & 97.37 & 2.37 \\
\hline & 150 & $143.43 \pm 2.85$ & 96.95 & 1.96 \\
\hline & 400 & $392.84 \pm 3.16$ & 98.21 & 0.81 \\
\hline & \multicolumn{4}{|l|}{ Stored at $-20{ }^{\circ} \mathrm{C}$ for 30 days } \\
\hline & 15 & $15.03 \pm 0.28$ & 100.18 & 1.84 \\
\hline & 150 & $144.83 \pm 3.90$ & 96.55 & 2.69 \\
\hline & 400 & $393.64 \pm 3.05$ & 98.41 & 0.77 \\
\hline
\end{tabular}

\subsection{Metabolic Stability}

The ENF and BNB levels in the HLM matrix were estimated using their peak area ratios in a linear calibration curve regression equation. Metabolic stability curves were constructed for ENF and BNB, both separately and mixed (Figure 7). The slopes of the linear regression equations of the constructed curves were used to calculate the in vitro $t_{1 / 2}$. The regression equations were $y=-0.0161 x+4.6059$ for ENF alone $\left(R^{2}=0.9997\right)$, $y=-0.0151 x+4.6042$ for ENF mixed with BNB $\left(R^{2}=0.9906\right), y=-0.0115 x+4.6096$ for 
BNB alone $\left(R^{2}=0.9757\right)$, and $y=-0.0119 x+4.605$ for BNB mixed with ENF $\left(R^{2}=0.9817\right)$ (Table 5).
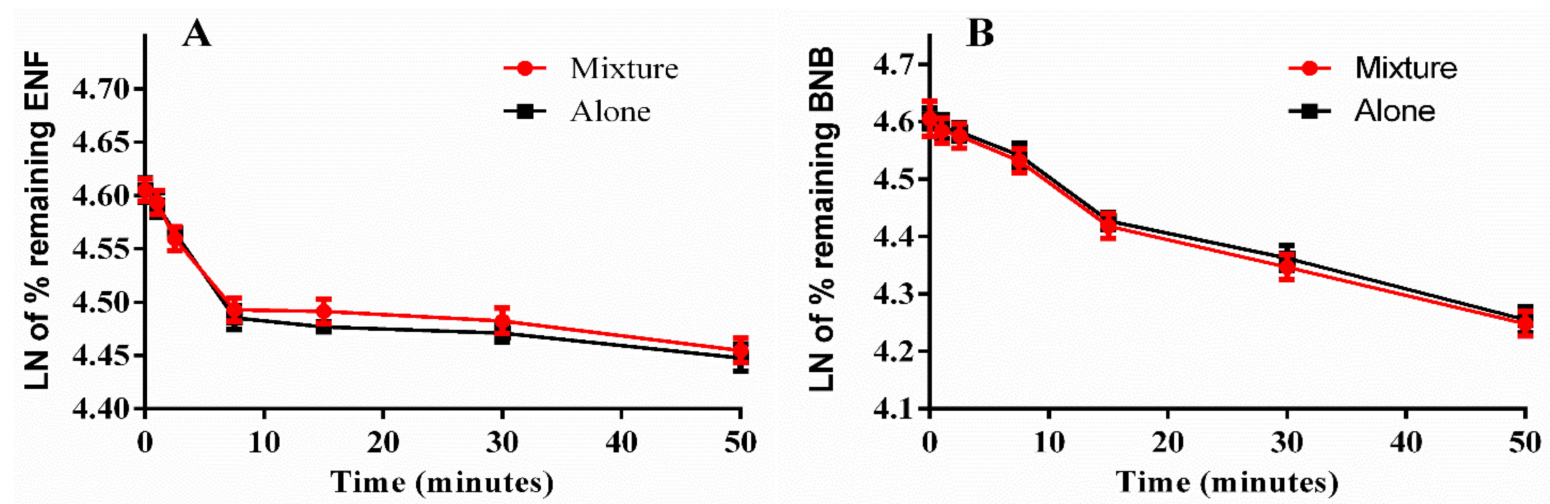

Figure 7. Metabolic stability curves of ENF alone and in a mixture with BNB (A) and BNB alone and in mixture with ENF (B).

Table 5. ENF and BNB metabolic stability parameters after incubation with HLMs.

\begin{tabular}{ccccc}
\hline \multirow{2}{*}{ Parameters } & \multicolumn{2}{c}{ ENF } & & BNB \\
\cline { 2 - 5 } & ENF Alone & ENF with BNB & BNB Alone & BNB with ENF \\
\hline Regression equation $^{\mathrm{a}}$ & $\mathrm{y}=-0.0161 \mathrm{x}+4.6059$ & $\mathrm{y}=-0.0151 \mathrm{x}+4.6042$ & $\mathrm{y}=-0.0115 \mathrm{x}+4.6096$ & $\mathrm{y}=-0.0119 \mathrm{x}+4.605$ \\
\hline Slope & 0.0161 & 0.0151 & 0.0115 & 0.0119 \\
\hline $\mathrm{t}_{1 / 2}{ }^{\mathrm{b}}$ & $43.1 \mathrm{~min}$ & $45.9 \mathrm{~min}$ & $60.3 \mathrm{~min}$ & $58.2 \mathrm{~min}$ \\
\hline $\mathrm{CLint}^{\mathrm{c}}$ & $16.09 \mu \mathrm{L} / \mathrm{min} / \mathrm{mg}$ & $15.09 \mu \mathrm{L} / \mathrm{min} / \mathrm{mg}$ & $11.49 \mu \mathrm{L} / \mathrm{min} / \mathrm{mg}$ & $11.89 \mu \mathrm{L} / \mathrm{min} / \mathrm{mg}$ \\
\hline $\mathrm{R}^{2 \mathrm{~d}}$ & 0.9972 & 0.9906 & 0.9757 & 0.9817 \\
\hline
\end{tabular}

${ }^{a}$ Regression equation in the linear part of metabolic stability curve. ${ }^{b}$ Half-life. ${ }^{c}$ Intrinsic clearance. ${ }^{\mathrm{d}}$ Determination coefficient.

The slope of each regression equation was used to estimate the in vitro $t_{1 / 2}$ using the following equations:

$$
\begin{aligned}
& \text { In vitro } t_{1 / 2}=\ln 2 / \text { slope } \\
& \text { In vitro } t_{1 / 2}=0.693 / \text { slope }
\end{aligned}
$$

Similarly, the $\mathrm{CL}_{\text {int }}$ of ENF and BNB was calculated following the in vitro $\mathrm{t}_{1 / 2}$ method (15) using the following equation:

$$
\begin{aligned}
& \mathrm{CL}_{\text {int, }}=\frac{0.693}{\text { in vitro } \mathrm{t}_{1 / 2}} \cdot \frac{\mu \mathrm{L} \text { incubation }}{\mathrm{mg} \text { microsomes }} \\
& \mathrm{CL}_{\text {int }}=\frac{0.693}{\text { in vitro t }_{1 / 2}} \cdot \frac{1000}{1}
\end{aligned}
$$

A validated LC-MS/MS method was developed for the simultaneous estimation of ENF and BNB that is characterized by sensitivity, rapidity (run time $=6 \mathrm{~min}$ ), high recovery, and accuracy. This method was applied for studying the metabolic stability of ENF and BNB. The ENF and BNB metabolic stability calculations showed moderate $\mathrm{CL}_{\mathrm{int}}$ (16.09 and $11.49 \mu \mathrm{L} / \mathrm{min} / \mathrm{mg}$ ) and in vitro $\mathrm{t}_{1 / 2}(43.1$ and $60.3 \mathrm{~min})$. Our calculations showed that when ENF and BNB are used concurrently, ENF is metabolized slightly slower, and BNB is metabolized slightly faster (Table 5). ENF is primarily metabolized through the CYP3A4 catalyzed phase I metabolism. In contrast, BNB is primarily metabolized by the UGT1A1 catalyzed conjugation and, to a lesser extent, by CYP1A2 and 2C19 catalyzed phase I metabolism [6-8], which supports our results of no significant effect on the metabolic stability of ENF and BNB when co-administered. These data and other parameters could 
also predict $\mathrm{BNB}$ and ENF in vivo pharmacokinetics using the Cloe PK simulation software. Furthermore, there does not appear to be any significant influence of ENF or BNB on each other's metabolic stability or metabolic disposition when used concurrently; consequently, it is unnecessary to recalculate doses for concurrent use of ENF and BNB. From metabolic stability data, we can advise that plasma levels should be measured in cases where these drugs are used together since they can accumulate to toxic levels.

\section{Materials and Methods}

\subsection{Chemicals and Reagents}

HPLC-grade water was prepared by an in-house Milli-Q plus filtration system procured from Millipore (Millipore, Bedford, MA, USA). All reagents and solvents used were of analytical grade. Acetonitrile and formic acid were procured from Sigma-Aldrich (West Chester, PA, USA). ENF, BNB, and avitinib (AVB) were procured from Med Chem Express (Monmouth Junction, NJ, USA). Pooled male HLMs (product number: M 0567) were purchased from Sigma-Aldrich (West Chester, PA, USA) and stored at $-70{ }^{\circ} \mathrm{C}$ until used. HLMs included a mixture of liver microsomes pooled from different individual male human donors.

\subsection{In Silico Prediction of ENF and BNB Metabolic Vulnerability and Toxicity Using StarDrop WhichP450 and DEREK Modules}

Before starting practical metabolic stability experiments, drugs should be tested for lability to drug metabolism in the liver. In silico metabolic stability for ENF and BNB was investigated using the WhichP450 ${ }^{\mathrm{TM}}$ module of StarDrop software (Optibrium Ltd. Cambridge, MA, USA). Additionally, a literature review indicated that ENF and BNB are subjected to metabolism in the liver. Identification of ENF and BNB stability in terms of metabolism was provided by the composite site lability (CSL). The results from the WhichP450 module are shown by the pie chart and used for indications of the most likely cyp450 isoform that has a significant role in ENF and BNB metabolism. Screening for the predicted toxicity of ENF and BNB was performed using DEREK software that was also utilized to screen for their structural alerts.

\subsection{LC-MS/MS Methodology}

An Agilent 1200 HPLC (Agilent Technologies, Palo Alto, CA, USA) was used for chromatographic separation of analytes, and an Agilent 6410 QqQ triple quadrupole (Agilent Technologies, Palo Alto, CA, USA) equipped with ESI was used for the generation and detection of the eluted analyte ions. Agilent Mass Hunter software (Agilent Technologies, Palo Alto, CA, USA) was used for instrument data analysis and control. LC-MS/MS analytical parameters were optimized to achieve optimum separation of ENF, BNB, and AVB; AVB was used as an internal standard (IS) (Table 6). We used Agilent triple quadrupole mass analyzer operated in the positive ion mode with electrospray ionization (ESI) for mass analysis. Nitrogen $(12 \mathrm{~L} / \mathrm{min})$ was used to dry the spray in the ESI source and the collision cell (60 psi) for dissociation studies. Direct injection was used to optimize all mass spectrometric analytical parameters to achieve the highest ion intensity. ESI source temperature (T) was set at $350{ }^{\circ} \mathrm{C}$, while capillary voltage (V) was adjusted to $4000 \mathrm{~V}$. Data acquisition was managed with the Mass Hunter software (Agilent Technologies, Palo Alto, CA, USA). The multiple reaction monitoring (MRM) mode of the QqQ was used to increase the selectivity and avoid interference of the HLM matrix in estimating ENF, BNB, and the IS, thereby elevating the LC-MS/MS method's sensitivity [38-40]. 
Table 6. LC-MS/MS methodology parameters.

\begin{tabular}{|c|c|c|c|}
\hline \multicolumn{2}{|c|}{ Agilent 1200 HPLC } & \multicolumn{2}{|c|}{ Triple Quadrupole 6410 QqQ } \\
\hline \multirow{4}{*}{ Isocratic mobile phase } & $\mathrm{ACN}(38 \%)$ & \multirow{6}{*}{ ESI source } & Positive mode \\
\hline & $\begin{array}{c}10 \mathrm{mM} \text { ammonium formate in } \mathrm{H}_{2} \mathrm{O} \\
(62 \%) \text { adjusted with formic acid } \\
\text { to } \mathrm{pH} 3.8\end{array}$ & & $\begin{array}{l}\text { Drying gas: } \mathrm{N}_{2} \text { gas } \\
\text { Pressure }(60 \mathrm{psi})\end{array}$ \\
\hline & Injection volume: $2 \mu \mathrm{L}$ & & Flow rate $(12 \mathrm{~L} / \mathrm{min})$ \\
\hline & Flow rate: $0.2 \mathrm{~mL} / \mathrm{min}$ & & \\
\hline \multirow{4}{*}{ Agilent Hypersil BDS-C18 } & \multirow{4}{*}{$\begin{array}{l}\text { Length } 125 \mathrm{~mm}, \\
\text { fully porous particle size }(3.0 \mu \mathrm{m}) \text { and } \\
\text { internal diameter }(2.0 \mathrm{~mm})\end{array}$} & & Source temperature: $350^{\circ} \mathrm{C}$ \\
\hline & & & Capillary voltage: $4000 \mathrm{~V}$ \\
\hline & & Mode & MRM mode \\
\hline & & Collision cell gas & Nitrogen with high purity \\
\hline \multirow{4}{*}{ Analytes } & \multirow[b]{2}{*}{ Binimetinib (BNB) } & \multirow[b]{2}{*}{ BNB MRM transitions } & $\begin{array}{c}\mathrm{m} / \mathrm{z} 441 \rightarrow \mathrm{m} / \mathrm{z} 379, \text { FVa: } 140 \mathrm{~V}, \\
\text { CEb: of } 22 \mathrm{eV}\end{array}$ \\
\hline & & & $\begin{array}{c}\mathrm{m} / \mathrm{z} 441 \rightarrow \mathrm{m} / \mathrm{z} 165, \mathrm{FV}: 140 \mathrm{~V}, \\
\text { CE: of } 20 \mathrm{eV}\end{array}$ \\
\hline & \multirow{2}{*}{ Encorafenib (ENF) } & \multirow{2}{*}{ ENF MRM Transitions } & $\begin{array}{c}\mathrm{m} / \mathrm{z} 540 \rightarrow \mathrm{m} / \mathrm{z} \text { 508, FV: } 135 \mathrm{~V}, \\
\text { CE: } 18 \mathrm{eV}\end{array}$ \\
\hline & & & $\begin{array}{c}\mathrm{m} / \mathrm{z} 540 \rightarrow \mathrm{m} / \mathrm{z} 359, \mathrm{FV}: 140 \mathrm{~V} \\
\text { CE: } 20 \mathrm{eV}\end{array}$ \\
\hline \multirow{2}{*}{ IS } & \multirow{2}{*}{ Avitinib (AVB) } & \multirow{2}{*}{ AVB MRM transitions } & $\begin{array}{c}\mathrm{m} / \mathrm{z} 488 \rightarrow \mathrm{m} / \mathrm{z} 433, \mathrm{FV}: 145 \mathrm{~V} \\
\text { CE: of } 15 \mathrm{eV}\end{array}$ \\
\hline & & & $\begin{array}{c}\mathrm{m} / \mathrm{z} 488 \rightarrow \mathrm{m} / \mathrm{z} 403, \mathrm{FV}: 145 \mathrm{~V} \\
\text { CE: of } 16 \mathrm{eV}\end{array}$ \\
\hline
\end{tabular}

\footnotetext{
${ }^{\mathrm{a}}$ Fragmentor voltage. ${ }^{\mathrm{b}}$ Collison energy.
}

\subsection{Standard Solutions of ENF and BNB}

$\mathrm{ENF}, \mathrm{BNB}$, and AVB are freely soluble in DMSO; accordingly, the first stocks were prepared for each of these compounds in DMSO at a $1 \mathrm{mg} / \mathrm{mL}$ concentration. We subsequently conducted serial dilution of the stock solutions with the optimized mobile phase to obtain stocks (S1) for ENF and BNB at a $100 \mu \mathrm{g} / \mathrm{mL}$ concentration. The S1 stocks were then serially diluted with mobile phase to obtain stocks (S2) for ENF and BNB at a $10 \mu \mathrm{g} / \mathrm{mL}$ concentration. The AVB stock was dissolved in DMSO to obtain a $100 \mu \mathrm{g} / \mathrm{mL}$ concentration that was then serially diluted with the mobile phase to obtain a stock (S3) of AVB at a $1 \mu \mathrm{g} / \mathrm{mL}$ concentration.

\subsection{Preparation of Calibration Standards}

BNB S2 $(10 \mu \mathrm{g} / \mathrm{mL})$ and ENF S2 $(10 \mu \mathrm{g} / \mathrm{mL})$ were diluted with a specific HLM matrix in phosphate buffer (1 mg protein $/ \mathrm{mL}$ ) to generate 13 standard levels: 5, 10, 15, 20, 30, 50, $80,100,150,200,300,400$, and $500 \mathrm{ng} / \mathrm{mL}$. The 15,150 , and $400 \mathrm{ng} / \mathrm{mL}$ levels were selected as low quality control (LQ), medium quality control (MQ), and high quality control (HQ), respectively. AVB S3 $(100 \mu \mathrm{L} / \mathrm{mL})$ was used as an IS.

\subsection{BNB and ENF Extraction from HLM Matrix}

The sample extraction procedure's target is to attain a high extraction percentage and decrease the biological matrix's effect to increase the sensitivity and reliability of the established LC-MS/MS method. A low detection limit characterized the quantification of analytes using LC-MS/MS methodology compared with the HPLC method; therefore, the analytes were extracted successfully with a low matrix effect and good recovery. The ACN protein precipitation extraction procedure is a standard method for metabolic stability experiments [41-44]. Therefore, the protein precipitation method was chosen as it is characterized by short preparation time, fewer extraction steps, and simplicity if compared with solid extraction or liquid-liquid extraction. Therefore, $\mathrm{ACN}$ was used as a protein 
precipitation method to extract the BNB, ENF, and AVB analytes from the HLM matrix, followed by thermostatted centrifugation at $14,000 \mathrm{rpm}$ and $4{ }^{\circ} \mathrm{C}$ for $15 \mathrm{~min}$. Supernatants were filtered into $1.5 \mathrm{~mL}$ HPLC vials using $0.22 \mu \mathrm{m}$ pore syringe filters. Five microliters of each sample were then injected into the LC-MS/MS for analysis.

Similarly, blank samples were prepared using phosphate buffer without the HLM matrix to confirm that the HLM matrix did not interfere with analyte retention times. The calibration curve of ENF was established by plotting the peak area ratio of ENF to AVB ( $y$-axis) against the nominal concentration ( $x$-axis) of ENF. The BNB calibration curve was established by plotting the peak area ratio of BNB to AVB (y-axis) against the nominal values ( $\mathrm{x}$-axis) of $\mathrm{BNB}$. We used a linear regression equation to validate the developed method's linearity; we calculated the slope, the coefficient of determination $\left(R^{2}\right)$, and intercept values.

\subsection{Method Validation}

The guidelines for analytical method validation of the FDA were followed for validation [45]. Method validation was performed for linearity, selectivity, sensitivity, precision, accuracy, extraction recovery, stability, and matrix effect [46]. We used the least-squares statistical method to compute the calibration curve equations $(y=m x+b)$. Determination coefficient $\mathrm{R}^{2}$ was used to confirm the linearity of the constructed calibration curve.

\subsubsection{Specificity, Linearity, and Sensitivity}

Analytical method specificity was investigated by the extraction of blank HLMs using the same extraction procedure. These extracts were then injected into the LC-MS/MS system and tested for any interference peaks for the retention time of BNB, ENF, and AVB.

Linearity and sensitivity of the developed analytical method were assessed using 12 calibration curves of BNB and ENF prepared on the first day of validation. The average from all data was used to establish a calibration curve for BNB and ENF. We performed back-calculations of the 12 calibration curves (calibration standards and QC samples) of ENF and BNB in the HLM matrix, which showed good performance of the methodology. The results of the 12 calibration curves were used for linearity confirmation and intraday validation.

\subsubsection{Accuracy, Precision, and Stability}

The accuracy and precision of the proposed method were investigated inter- and intra-day. The intra- and inter-day accuracy and precision values were calculated according to USFDA guidelines [42]. The stability of ENF and BNB in different conditions, room temperature for $8 \mathrm{~h}$, three freeze-thaw cycles, and storage at $4{ }^{\circ} \mathrm{C}$ for $24 \mathrm{~h}$ and at $-20^{\circ} \mathrm{C}$ for $30 \mathrm{~d}$, were examined.

\subsubsection{Matrix Effect and Extraction Recovery}

The recovery and matrix effects in HLMs were investigated using QC samples, including low quality control, medium quality control, and high quality control. The recovery of BNB and ENF from HLMs was determined by comparing the peak area ratio response of both analytes in the optimized mobile phase (A) and those after protein precipitation (B). The ratio of $\mathrm{B} / \mathrm{A} \times 100$ is defined as the percentage recovery. The matrix effect was determined by dividing the response of the post-extraction spiked sample (B) to the extracted BNB or ENF sample (C). Matrix effect equals $(C / B \times 100)$. A deviation in BNB and ENF by a maximum of $3.2 \%$ was considered an acceptable range, as recommended by the European guideline on bioanalytical method validation [47-49].

\subsection{Metabolic Stability Assessment of BNB and ENF}

BNB and ENF concentration during HLM incubation was adjusted to $1 \mu \mathrm{M}$ to ensure that it was less than the Michaelis-Menten constant and constructed a linear relationship between the ratio of metabolism and incubation time. HLMs $(1 \mathrm{mg} / \mathrm{mL})$ in phosphate 
buffer were used to confirm the absence of nonspecific protein binding. We performed metabolic stability assessments for ENF and BNB by measuring the decrease in ENF and BNB concentrations after incubation with an HLM matrix. One micromole from ENF and BNB was incubated with HLM (1 mg protein in $1 \mathrm{~mL}$ phosphate buffer) in triplicate. The metabolic reaction medium was phosphate buffer ( $\mathrm{pH} 7.4$ ) containing $3.3 \mathrm{mM} \mathrm{MgCl}$. The metabolic mixture was pre-incubated in a $37^{\circ} \mathrm{C}$ water bath for $10 \mathrm{~min}$ for temperature conditioning. NADPH $(1 \mathrm{mM})$ was used for the initiation of the metabolic reaction, after which $2 \mathrm{~mL}$ ACN was used to terminate the reaction at specific time intervals $(0,1,2.5$, $7.5,15,30$, and $50 \mathrm{~min}$ ), allowing us to establish metabolic stability curves for ENF and BNB. We conducted this metabolic experiment for ENF alone, BNB alone, and a mixture of ENF and BNB to evaluate the metabolic stability of BNB and ENF alone and combined. The proportion of BNB and ENF remaining either alone or combined was plotted versus incubation time. From this plot, time points in the linear range were selected to plot the natural logarithm (ln) of the remaining proportions of ENF and BNB versus time. The slope of the linear part indicated the rate constant for ENF and BNB disappearance that was used for in vitro $t_{1 / 2}$ calculation using equation (1). Then, ENF and BNB $C L_{\text {int }}$ values, either alone or combined, were calculated by applying the following Equation (3) [50-52].

\section{Conclusions}

We established a validated LC-MS/MS method for the simultaneous estimation of ENF and BNB. The established method is sensitive, rapid (run time $=6 \mathrm{~min}$ ), has a high recovery, and is accurate. ENF and BNB were each characterized by a moderate $\mathrm{CL}_{\text {int }}$ $(16.09 \mu \mathrm{L} / \mathrm{min} / \mathrm{mg}$ for ENF and $11.49 \mu \mathrm{L} / \mathrm{min} / \mathrm{mg}$ for BNB$)$ and a moderate in vitro $t_{1 / 2}$ (43.1 min for ENF and $60.3 \mathrm{~min}$ for BNB), revealing a moderate clearance of ENF and BNB from the blood by the liver. This indicates a probable good in vivo bioavailability, which corroborates the good oral bioavailability previously reported. Additionally, these results indicate that ENF and BNB will slowly bioaccumulate after multiple doses.

Furthermore, there does not appear to be any significant influence of ENF or BNB on each other's metabolic stability or metabolic disposition when used concurrently; consequently, it is unnecessary to recalculate doses for concurrent use of ENF and BNB. We can advise that plasma levels should be measured in cases where these drugs are used together since they can accumulate to toxic levels. The experimental outcomes were supported by the in silico WhichP450 ${ }^{\mathrm{TM}}$ module of StarDrop software (Optibrium Ltd. Cambridge, MA, USA). In silico toxicological studies for ENF and BNB were performed using DEREK software that revealed structural alerts and proposed side effects. Further drug discovery experiments can be performed depending on these outcomes, permitting a new series of drugs with increased metabolic stability.

Author Contributions: A.A.K., M.W.A., and H.W.D. designed the study. H.W.D., M.W.A., and A.A.K. supervised the practical work. M.W.A., N.S.A.-S., and H.W.D. performed the method optimization and validation studies. M.W.A. drafted the first version of the manuscript. All authors have read and agreed to the published version of the manuscript.

Funding: The Deanship of Scientific Research at King Saud University through Research Group Project No. RGP-322.

Institutional Review Board Statement: The in vitro experiments (assays using commercially available human liver microsomes) are exempt from the need for approval by the Research Ethics Committee at King Saud University.

Informed Consent Statement: Not applicable.

Data Availability Statement: All data are available within the manuscript.

Acknowledgments: The authors would like to extend their sincere appreciation to the Deanship of Scientific Research at King Saud University for funding this work through Research Group Project No. RGP-322.

Conflicts of Interest: The authors declare that no competing interests exist. 
Sample Availability: The samples of compounds are not available from the authors.

\section{References}

1. Cummins, D.L.; Cummins, J.M.; Pantle, H.; Silverman, M.A.; Leonard, A.L.; Chanmugam, A. Cutaneous Malignant Melanoma. Mayo Clin. Proc. 2006, 81, 500-507. [CrossRef] [PubMed]

2. Hall, C.S.; Ross, M.; Bauldry, J.B.B.; Upshaw, J.; Karhade, M.G.; Royal, R.; Patel, S.; Lucci, A. Circulating tumor cells in Stage IV melanoma patients. J. Am. Coll. Surg. 2018, 227, 116-124. [CrossRef] [PubMed]

3. Raedler, L.A. Braftovi (Encorafenib) Plus Mektovi (Binimetinib) Third BRAF/MEK Inhibition Combination Approved for Metastatic Melanoma with BRAF Mutation. Available online: https://www.ahdbonline.com/select-drug-profiles/2756-braftoviencorafenib-plus-mektovi-binimetinib-third-braf-mek-inhibition-combination-approved-for-metastatic-melanoma-with-brafmutation (accessed on 15 June 2020).

4. Meier, F.; Schittek, B.; Busch, S.; Garbe, C.; Smalley, K.; Satyamoorthy, K.; Li, G.; Herlyn, M. The RAS/RAF/MEK/ERK and PI3K/AKT signaling pathways present molecular targets for the effective treatment of advanced melanoma. Front. Biosci. 2005, 10, 2986-3001. [CrossRef] [PubMed]

5. Zhang, L.; Zhou, F.; Dijke, P. Signaling interplay between transforming growth factor- $\beta$ receptor and PI3K/AKT pathways in cancer. Trends Biochem. Sci. 2013, 38, 612-620. [CrossRef] [PubMed]

6. Trojaniello, C.; Festino, L.; Vanella, V.; Ascierto, P.A. Encorafenib in combination with binimetinib for unresectable or metastatic melanoma with BRAF mutations. Expert Rev. Clin. Pharmacol. 2019, 12, 259-266. [CrossRef] [PubMed]

7. Sun, J.; Zager, J.S.; Eroglu, Z. Encorafenib/binimetinib for the treatment of BRAF-mutant advanced, unresectable, or metastatic melanoma: Design, development, and potential place in therapy. OncoTargets Ther. 2018, 11, 9081-9089. [CrossRef] [PubMed]

8. Shirley, M. Encorafenib and Binimetinib: First global approvals. Drugs 2018, 78, 1277-1284. [CrossRef] [PubMed]

9. Turner, M.C.; Rossfeld, K.; Salama, A.K.; Tyler, D.; Beasley, G. Can binimetinib, encorafenib and masitinib be more efficacious than currently available mutation-based targeted therapies for melanoma treatment? Expert Opin. Pharmacother. 2017, 18, 487-495. [CrossRef]

10. Dummer, R.; Ascierto, P.A.; Gogas, H.J.; Arance, A.; Mandala, M.; Liszkay, G.; Garbe, C.; Schadendorf, D.; Krajsova, I.; Gutzmer, R.; et al. Encorafenib plus binimetinib versus vemurafenib or encorafenib in patients with BRAF-mutant melanoma (COLUMBUS): A multicentre, open-label, randomised phase 3 trial. Lancet Oncol. 2018, 19, 603-615. [CrossRef]

11. Di, L. The role of drug metabolizing enzymes in clearance. Expert Opin. Drug Metab. Toxicol. 2014, 10, 379-393. [CrossRef]

12. Wienkers, L.C.; Heath, T.G. Predicting in vivo drug interactions from in vitro drug discovery data. Nat. Rev. Drug Discov. 2005, 4, 825-833. [CrossRef]

13. Pelkonen, O.; Turpeinen, M.; Uusitalo, J.; Rautio, A.; Raunio, H. Prediction of drug metabolism and interactions on the basis of in vitro investigations. Basic Clin. Pharmacol. Toxicol. 2005, 96, 167-175. [CrossRef]

14. Coecke, S.; Ahr, H.; Blaauboer, B.J.; Bremer, S.; Casati, S.; Castell, J.; Combes, R.; Corvi, R.; Crespi, C.L.; Cunningham, M.L. Metabolism: A bottleneck in in vitro toxicological test development: The report and recommendations of ECVAM workshop 54. Altern. Lab. Anim. 2006, 34, 49-84. [CrossRef]

15. Eddershaw, P.J.; Beresford, A.P.; Bayliss, M.K. ADME/PK as part of a rational approach to drug discovery. Drug Discov. Today 2000, 5, 409-414. [CrossRef]

16. Kola, I.; Landis, J. Can the pharmaceutical industry reduce attrition rates? Nat. Rev. Drug Discov. 2004, 3, 711-716. [CrossRef]

17. Khanna, I. Drug discovery in pharmaceutical industry: Productivity challenges and trends. Drug Discov. Today 2012, 17, 1088-1102. [CrossRef]

18. Ulenberg, S.; Bączek, T. Metabolic stability studies of lead compounds supported by separation techniques and chemometrics analysis. J. Sep. Sci. 2021, 44, 373-386. [CrossRef]

19. Attwa, M.W.; Kadi, A.A.; Abdelhameed, A.S. Phase I metabolic profiling and unexpected reactive metabolites in human liver microsome incubations of X-376 using LC-MS/MS: Bioactivation pathway elucidation and in silico toxicity studies of its metabolites. RSC Adv. 2020, 10, 5412-5427. [CrossRef]

20. Attwa, M.W.; Kadi, A.A.; Abdelhameed, A.S. Detection and characterization of olmutinib reactive metabolites by LC-MS/MS: Elucidation of bioactivation pathways. J. Sep. Sci. 2020, 43, 708-718. [CrossRef]

21. Meirson, T.; Asher, N.; Bomze, D.; Markel, G. Safety of BRAF + MEK Inhibitor Combinations: Severe Adverse Event Evaluation. Cancers 2020, 12, 1650. [CrossRef]

22. Matsudate, Y. Case of inflammatory arthritis induced by encorafenib and binimetinib in a patient with melanoma. J. Dermatol. 2020, 47. [CrossRef]

23. Lièvre, A.; de la Fouchardière, C.; Samalin, E.; Benoist, S.; Phelip, J.M.; André, T.; Lledo, G. BRAF V600E-mutant colorectal cancers: Where are we? Bull. Cancer 2020, 107, 881-895. [CrossRef]

24. Sullivan, R.J.; Weber, J.S.; Patel, S.P.; Dummer, R.; Carlino, M.S.; Tan, D.S.; Lebbe, C.; Siena, S.; Élez, E.; Wollenberg, L.; et al. A phase $1 b / 2$ study of the BRAF inhibitor encorafenib plus the MEK inhibitor binimetinib in patients with BRAF V600E/K-mutant solid tumors. Clin. Cancer Res. 2020, 26, 5102-5112. [CrossRef]

25. Baranczewski, P.; Stańczak, A.; Sundberg, K.; Svensson, R.; Wallin, A.; Jansson, J.; Garberg, P.; Postlind, H. Introduction to in vitro estimation of metabolic stability and drug interactions of new chemical entities in drug discovery and development. Pharmacol. Rep. 2006, 58, 453-472. 
26. Rousset, M.; Titier, K.; Bouchet, S.; Dutriaux, C.; Pham-Ledard, A.; Prey, S.; Canal-Raffin, M.; Molimard, M. An UPLC-MS/MS method for the quantification of BRAF inhibitors (vemurafenib, dabrafenib) and MEK inhibitors (cobimetinib, trametinib, binimetinib) in human plasma. Application to treated melanoma patients. Clin. Chim. Acta 2017, 470, 8-13. [CrossRef]

27. Sparidans, R.W.; Rosing, H.; Rood, J.J.M.; Schellens, J.H.M.; Beijnen, J.H. Liquid chromatography-tandem mass spectrometric assay for therapeutic drug monitoring of the B-Raf inhibitor encorafenib, the EGFR inhibitors afatinib, erlotinib and gefitinib and the O-desmethyl metabolites of erlotinib and gefitinib in human plasma. J. Chromatogr. B Anal. Technol. Biomed. Life Sci. 2016, 1033-1034, 390-398. [CrossRef]

28. Kadav, A.A.; Vora, D.N. Stability indicating UPLC method for simultaneous determination of atorvastatin, fenofibrate and their degradation products in tablets. J. Pharm. Biomed. Anal. 2008, 48, 120-126. [CrossRef]

29. Al Bratty, M. Stability-indicating UPLC Method for simultaneous analysis of protein kinase inhibitors, binimetinib, and encorafenib in pure active pharmaceutical ingredient (API) and formulation. Lat. Am. J. Pharm. 2020, 39, 1428-1436.

30. Huynh, H.H.; Pressiat, C.; Sauvageon, H.; Madelaine, I.; Maslanka, P.; Lebbé, C.; Thieblemont, C.; Goldwirt, L.; Mourah, S. Development and Validation of a Simultaneous Quantification Method of 14 Tyrosine Kinase Inhibitors in Human Plasma Using LC-MS/MS. Ther. Drug Monit. 2017, 39, 43-54. [CrossRef]

31. Jiang, H.; Zeng, J.; Titsch, C.; Voronin, K.; Akinsanya, B.; Luo, L.; Shen, H.; Desai, D.D.; Allentoff, A.; Aubry, A.F.; et al. Fully validated LC-MS/MS assay for the simultaneous quantitation of coadministered therapeutic antibodies in cynomolgus monkey serum. Anal. Chem. 2013, 85, 9859-9867. [CrossRef]

32. Van Erp, N.P.; de Wit, D.; Guchelaar, H.J.; Gelderblom, H.; Hessing, T.J.; Hartigh, J. A validated assay for the simultaneous quantification of six tyrosine kinase inhibitors and two active metabolites in human serum using liquid chromatography coupled with tandem mass spectrometry. J. Chromatogr. B Anal. Technol. Biomed. Life Sci. 2013, 937, 33-43. [CrossRef] [PubMed]

33. Attwa, M.W.; Kadi, A.A.; Alrabiah, H.; Darwish, H.W. LC-MS/MS reveals the formation of iminium and quinone methide reactive intermediates in entrectinib metabolism: In vivo and in vitro metabolic investigation. J. Pharm. Biomed. Anal. 2018, 160, 19-30. [CrossRef] [PubMed]

34. Rowland, M.; Benet, L.Z.; Graham, G.G. Clearance concepts in pharmacokinetics. J. Pharm. Biopharm. 1973, 1, 123-136. [CrossRef] [PubMed]

35. Wilkinson, G.R.; Shand, D.G. Commentary: A physiological approach to hepatic drug clearance. Clin. Pharm. 1975, 18, 377-390.

36. Houston, J.B. Utility of in vitro drug metabolism data in predicting in vivo metabolic clearance. Biochem. Pharm. 1994, 47, 1469-1479. [CrossRef]

37. Obach, R.S.; Baxter, J.G.; Liston, T.E.; Silber, B.M.; Jones, B.C.; MacIntyre, F.; Rance, D.J.; Wastall, P. The prediction of human pharmacokinetic parameters from preclinical and in vitro metabolism data. J. Pharm. Exp. 1997, 283, 46-58.

38. Inoue, K.; Yoshimi, Y.; Hino, T.; Oka, H. Simultaneous determination of avermectins in bovine tissues by LC-MS/MS. J. Sep. Sci. 2009, 32, 3596-3602. [CrossRef]

39. Surowiec, I.; Koc, M.; Antti, H.; Wikström, P.; Moritz, T. LC-MS/MS profiling for detection of endogenous steroids and prostaglandins in tissue samples. J. Sep. Sci. 2011, 34, 2650-2658. [CrossRef]

40. Shah, H.J.; Kundlik, M.L.; Patel, N.K.; Subbaiah, G.; Patel, D.M.; Suhagia, B.N.; Patel, C.N. Rapid determination of losartan and losartan acid in human plasma by multiplexed LC-MS/MS. J. Sep. Sci. 2009, 32, 3388-3394. [CrossRef]

41. Attwa, M.W.; Darwish, H.W.; Alhazmi, H.A.; Kadi, A.A. Investigation of metabolic degradation of new ALK inhibitor: Entrectinib by LC-MS/MS. Clin. Chim. Acta 2018, 485, 298-304.

42. Attwa, M.W.; Kadi, A.A.; Darwish, H.W.; Amer, S.M.; AlRabiah, H. LC-ESI-MS/MS identification and characterization of ponatinib in vivo phase I and phase II metabolites. Clin. Chim. Acta 2018, 485, 144-151. [CrossRef]

43. Attwa, M.W.; Kadi, A.A.; Abdelhameed, A.S. Reactive intermediates and bioactivation pathways characterization of avitinib by LC-MS/MS: In vitro metabolic investigation. J. Pharm. Biomed. Anal. 2019, 164, 659-667. [CrossRef]

44. Attwa, M.W.; Kadi, A.A.; Abdelhameed, A.S. Characterization of reactive intermediates formation in dacomitinib metabolism and bioactivation pathways elucidation by LC-MS/MS: In vitro phase I metabolic investigation. RSC Adv. 2018, 8, 38733-38744. [CrossRef]

45. Bioanalytical Method Validation Guidance for Industry. Available online: https:/ /www.fda.gov/regulatory-information/searchfda-guidance-documents/bioanalytical-method-validation-guidance-industry (accessed on 12 June 2020).

46. Attwa, M.W.; Kadi, A.A.; Darwish, H.W.; Amer, S.M.; Alrabiah, H. A reliable and stable method for the determination of foretinib in human plasma by LC-MS/MS: Application to metabolic stability investigation and excretion rate. Eur. J. Mass Spectrom. 2018, 24, 344-351. [CrossRef]

47. Darwish, H.W.; Kadi, A.A.; Attwa, M.W.; Almutairi, H.S. Investigation of metabolic stability of the novel ALK inhibitor brigatinib by liquid chromatography tandem mass spectrometry. Clin. Chim. Acta 2018, 480, 180-185. [CrossRef]

48. Smith, G. European Medicines Agency guideline on bioanalytical method validation: What more is there to say? Bioanalysis 2012, 4, 865-868. [CrossRef]

49. Manzo, A.; Montanino, A.; Costanzo, R.; Sandomenico, C.; Palumbo, G.; Schettino, C.; Daniele, G.; Morabito, A.; Perrone, F.; Piccirillo, M.C. Chapter 33-EGFR Mutations: Best Results from Second- and Third-Generation Tyrosine Kinase Inhibitors. In Oncogenomics; Dammacco, F., Silvestris, F., Eds.; Academic Press: Cambridge, MA, USA, 2019; pp. 477-486.

50. Amer, S.M.; Kadi, A.A.; Darwish, H.W.; Attwa, M.W. Liquid chromatography tandem mass spectrometry method for the quantification of vandetanib in human plasma and rat liver microsomes matrices: Metabolic stability investigation. Chem. Cent. J. 2017, 11, 45. [CrossRef] 
51. Caldwell, G.; Yan, Z. Optimization in Drug Discovery: In Vitro Methods; Springer Science \& Business Media: Berlin/Heidelberg, Germany, 2014.

52. Leahy, D.E. Integrating in vitro ADMET data through generic physiologically based pharmacokinetic models. Expert Opin. Drug Metab. Toxicol. 2006, 2, 619-628. [CrossRef] 